\title{
ON THE GOLGI-DERIVED VESICLES IN THE RABBIT TASTE BUD CELLS : AN ELECTRON MICROSCOPY AND RELATED CYTOCHEMISTRY
}

\author{
SUNAO FUJIMOTO \\ Department of Anatomy, Kurume University School of Medicine, \\ Kurume, Japan
}

(Received for publication September 11, 1973)

\begin{abstract}
Vesicles originated in the Golgi complex are found in the supranuclear areas of the taste bud cells in various concentrations, and they aggregate in a considerable number just beneath the apical surface membrane of the differentiating cells where microvilli are destined to form. This evidence adds further weights to a hypothesis that specialization of the cell surface arises partly by a mediation of the Golgi-derived vesicles.

In addition, the present cytochemistry also indicates that these Golgiderived vesicles are preformed units of the plasma membrane which carry surface coat material assembled in the Golgi complex to the apical surface membrane.
\end{abstract}

The considerable variation in appearance of the several cells comprising mammalian taste buds has been demonstrated in various ways. On this basis, we have classified rabbit taste bud cells into three types and designated them as cell type I (dark cells), cell type II (light cells) and cell type III (distinctly synaptic cells) ${ }^{10)}{ }^{16) 17)}$.

On the other hand, it has been demonstrated by Beidler and Smallman ${ }^{31}$ that cells in taste buds have a limited life span and are constantly replaced by newly differentiated ones from perigemmal epithelial cells. Therefore, one possibility must be considered that the variation in cell appearance may represent several transient forms of one functional cell type in the process from less-differentiated precursor cell to degenerated form. However, our recent observations on the de- and regenerating buds clearly demonstrated that the type I, II and III cells originate se- parately with different functions from a single less-differentiated form (the basal cells), mature and degenerate without transforming to the other cell types. ${ }^{8)}$ 9)

By an extensive observation of considerable large numbers of the normal buds, many profiles of such unmatured forms in various stages can be obtained and we have no inconsistency in feature between the unmatured cells in the reforming buds, and those in the normal ones.

The basal cells do not reach the taste pore nor possess microvilli specialization at the apical cell surface. A distinctly different stage in the further differentiation is reached when they begin to show characteristics which are peculiar to the other three cell types. During this stage, Golgi complex of these differentiating cells produces many vesicles different in structure and concentration between each cell type. A second 
event in this stage is an expansion of the free cell surface that is destined to microvilli specialization.

Descriptions will be made in this article on the fine structural features of these Golgi-derived vesicles and on their possible role for the formation of the microvilli as "surface forming vesicles". This interpretation may add further weights to a hypothesis based on findings of proximal tubular cells in kidney and absorptive cells in intestine that the microvilli specialization is formed by a mediation by the Golgiderived vesicles ${ }^{7)}{ }^{20)}$. In addition, the present cytochemistry indicates that these Golgi-derived vesicles are preformed units of the plasma membrane which carry surface coat materials to the free cell surface.

\section{MATERIALS AND METHODS}

Six adult rabbits were perfused from the left ventricle by $4 \%$ paraformaldehyde in $0.1 \mathrm{M}$ cacodylate buffer $(\mathrm{pH}$ 7.4). After the perfusion, the foliate papillae were isolated from the tongues and postfixed in a ice-cold $2 \%$ osmium tetroxide in the buffer for 2 hours.

For the cytochemical study for adenosine triphosphatase (ATPase) activity, some papillae after the perfusion were cut into $50 \mu$ thick frozen sections by a Cryo-Cut Microtome (American Optical Co.) and incubated in a medium of Wachstein-Meisel ${ }^{21}$. For the acetylcholinesterase activity, another group of sections were incubated in LewisShute medium ${ }^{12)}$, using cacodylate buffer. The animals for the acid mucopolysaccharide stainings were perfused by the $4 \%$ buffered paraformaldehyde con- taining $1500 \mathrm{ppm}$ ruthenium red ( $R R$, $\left[\left(\mathrm{NH}_{3}\right)_{5} \mathrm{Ru}-\mathrm{O}-\mathrm{Ru}\left(\mathrm{NH}_{3}\right)_{4}-\mathrm{O}-\mathrm{Ru}\left(\mathrm{NH}_{3}\right)_{5}\right]^{6+}$, Sigma Chemical Co.). After the perfusion, thick frozen sections by the Cryo-Cut were soaked in modified media of Luft ${ }^{13) 14}$. Mucopolysaccharide stainings were also done by Mowry's colloidal iron method ${ }^{15)}$. The materials after cytochemical procedures were re-fixed in the buffered $1 \%$ osmium tetroxide for one hour.

All the materials were dehydrated in graded acetones and embedded in epoxy resins. The thin sections were made by a Porter-Blum Ultramicrotome, and stained by uranyl acetate and lead hydroxide. Some sections for cytochemical observations were used without staining. Electron micrographs were taken by a Hitachi-11 type electron microscope.

\section{OBSERVATIONS AND INTERPRETA- TIONS}

\section{General architecture of the taste} buds (Figs. 1 and 2).

The taste bud (or gemma) is set in a layer of epithelium of the papillae and the taste pore can be seen as an opening in the surface epithelial cells. The taste bud cells are elongated fusiforme in shape and extend from the surface of the bud to the basal lamina of the epithelium. Each taste bud contains 50-80 cells which are designated as cell type I, II and III by their distinct cytoplasmic features. Detailed descriptions on each feature will be omitted in this article as we have already described in previous papers ${ }^{10)}{ }^{16}$ ) 17).

Fig. 1 Type I (T1), type II (T2) and type III cells (T3) are shown in a taste bud of foliate papilla. $\times 3,700$.

Fig. 2 In taste pit region, apical part of the taste bud cells becomes narrower and possessess microvilli specilization. Dense substances (DS) exist between the microvilli. $\times 15,000$. 


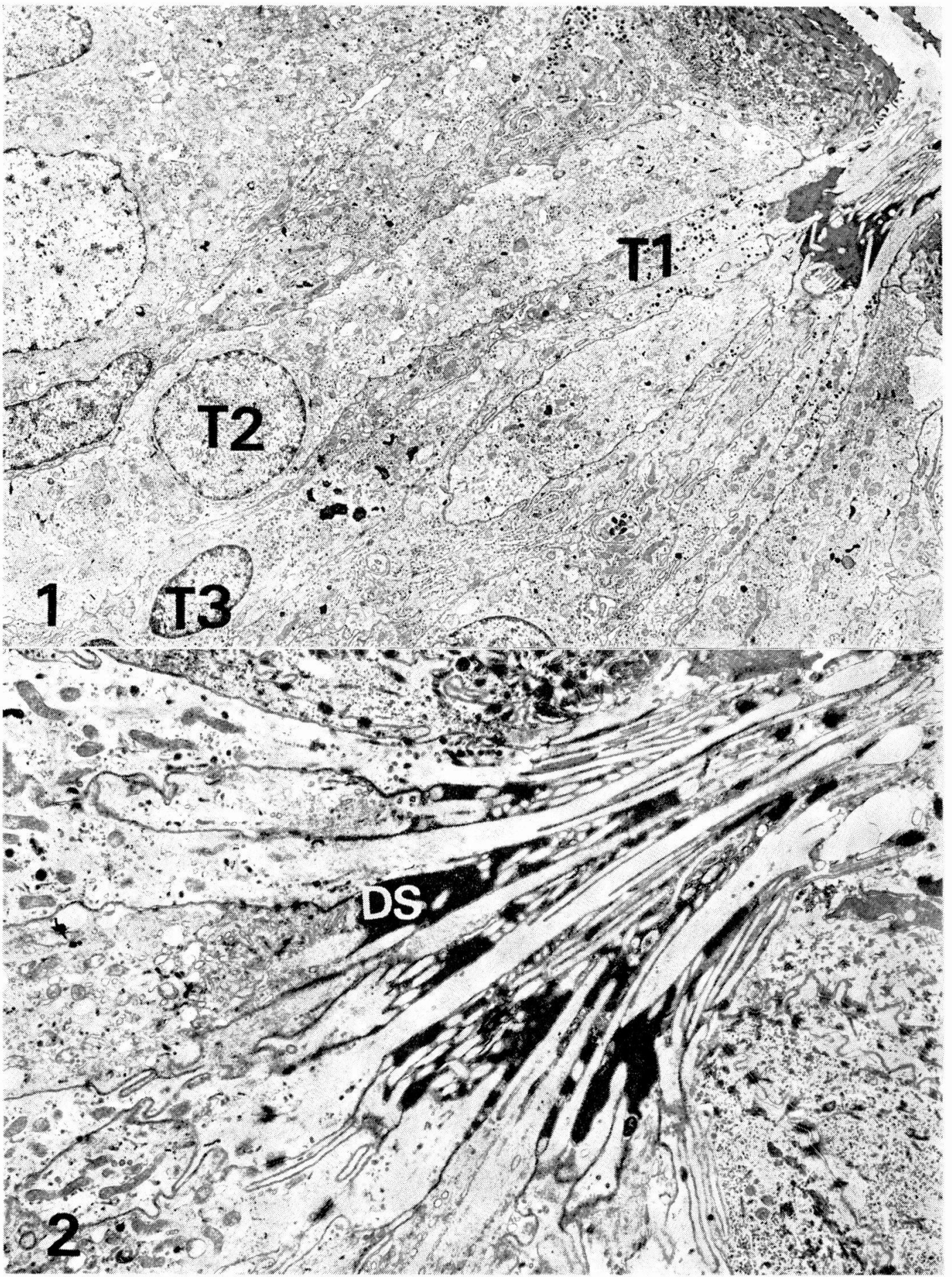


The lower half of the taste bud contains numerous nuclei, and a few are seen in the middle third. The cytoplasmic territories in the upper half of the bud become relatively narrower and form parallel processess of microvilli which extend the taste pore (the taste pit region). However, an apical termination of the type III cells is quite variable and will require extensive serial-section examinations for a complete description; unlike the type I and II cells, they often form one long, slender projection without having microvilli specialization.

Except for these three cell types of matured form, some cell profiles are found in the taste buds which do not fit precisely these categories. These include the basal cells and differentiating forms of each cell type. The former still does not have any feature designable as a cell type and is located in the lower region of the taste bud. The latter has already had some features of each cell type. The structure at the cell apex of the latter is quite variable and ranges between those which do not reach the taste pore without any microvilli specialization and those which have already reached the pore with differentiating microvilli. These features are quite difficult to say by random sectioned sampling but have precisely been examined by our previous observations of serially sectioned sampling ${ }^{16)}$.

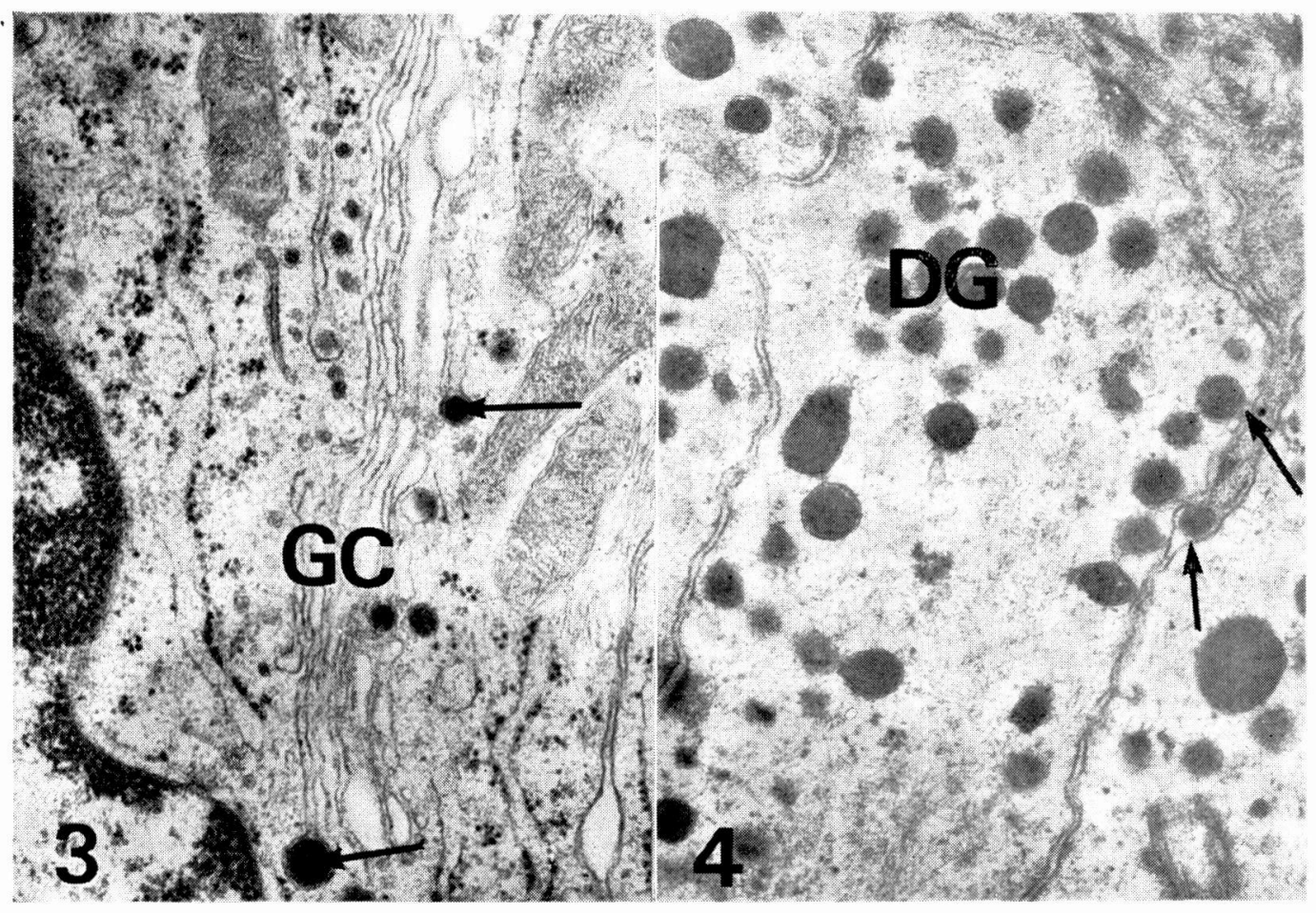

Fig. 3 Cisternae of Golgi complex (GC) in a differentiating type I cells, producing dark granules (arrows). $\times 31,000$.

Fig. 4 Dark granules (DG) aggregated in the cell apex of differentiating type I cells. Their fusion with the plasma membrane and export from the cell are noticed (arrows). $\times 36,000$. 


\section{Golgi-derived vesicles in the taste bud cells}

By a continuous cell renewal in the taste buds, the basal cells become modified into the type I, II and III cells by each distinct cytoplasmic feature.

Signal in the noticeable emergence of differentiation to a type I cell is dark granules formed in the Golgi complex since this process occurs exclusively in this type (Fig. 3). These granules are 1000-3000 $\AA$ in diameter, limited by the Golgi membrane, and occur throughout the cytoplasm between the Golgi complex near the cell base and the apical part of the cell.

An aggregation of these dark granules is often observed beneath the free surface of the type I cell. This is morepronounced in the differentiating form before and during the formation of the microvilli, and becomes less evident after the formation of the microvilli.

Secretory function of this cell type is emphasized by the fact that the dark granules are fused with the plasma membrane at the apical cell surface and those loosing their limiting membrane are often located between intercellular spaces in the taste pit region (Fig. 4), and also by our previous data that these events parallel the persistence of dense substance in the taste pore of reforming buds ${ }^{9}$. These finding:s indicate that the Golgi complex of the type I cells continues to produce many vesicles as the limiting membrane of the dark granules after the onset of the differentiation to this cell type, and that these Golgi-derived vesicles are constantly integrated into the plasma membrane at the cell apex before and during the morphogenesis of microvilli, involving the process of granule discharges by a reverse pinocytosis.

On the other hand, the Golgi complex of the type II cells does not produce such dark granules. It consists of cisternae and associated vesicles of 50 to $90 \mathrm{~m} \mu$ in diameter (Fig. 5). Some vesicles are acutually attached to the cisternae while others appear free. The limiting membrane of these vesicles is morphologically heterogeneous and changes from $75 \AA$ over to $100 \AA$ thick. Thus, the thickened vesicles (for convenience in descriptions, "thick-walled vesicles") appears to be the same in structure as that of the plasm membrane (Fig. 5). Furthermore, the cisternal membranes also show partial thickening of their unit structure and this is more marked in those cisternae towards the distal face of the stack than in those at the proximal face (Fig. 6). The Golgi-derived vesicles including thick-walled vesicles in the type II cells occur not only in the vicinity of the Golgi system but also throughout the cell cytoplasm. Their aggregation in the cell apex and their fusion with the apical plasma membrane are also noticed in this cell type (Fig. 7). Some of the thick-walled vesicles become fusiformig possibly by a fusion with each other (Fig. 8).

The Golgi-derived vesicles in the type III cell are not so many as those in the type I and II cells, and do not include secretory granules as found in the type I cells nor thick-walled vesicles as in the type II cells. However, a few profiles of vesicles derived from the Golgi complex occur in supranuclear cytoplasm and their fusion with the apical plasma membrane are also noted.

The type III cells contain other two kinds of vesicles, exclusively occurred in this type (Fig. 9). One is dark cored vesicles, uniformely spherical in form, ranges in diameter from 100 to $150 \mathrm{~m} \mu$, and has a densely staining core with the peripheral space. It can be clearly discriminated from a dark granule of the type I cell by their fine structure and also by exclusive acetylcholineste- 


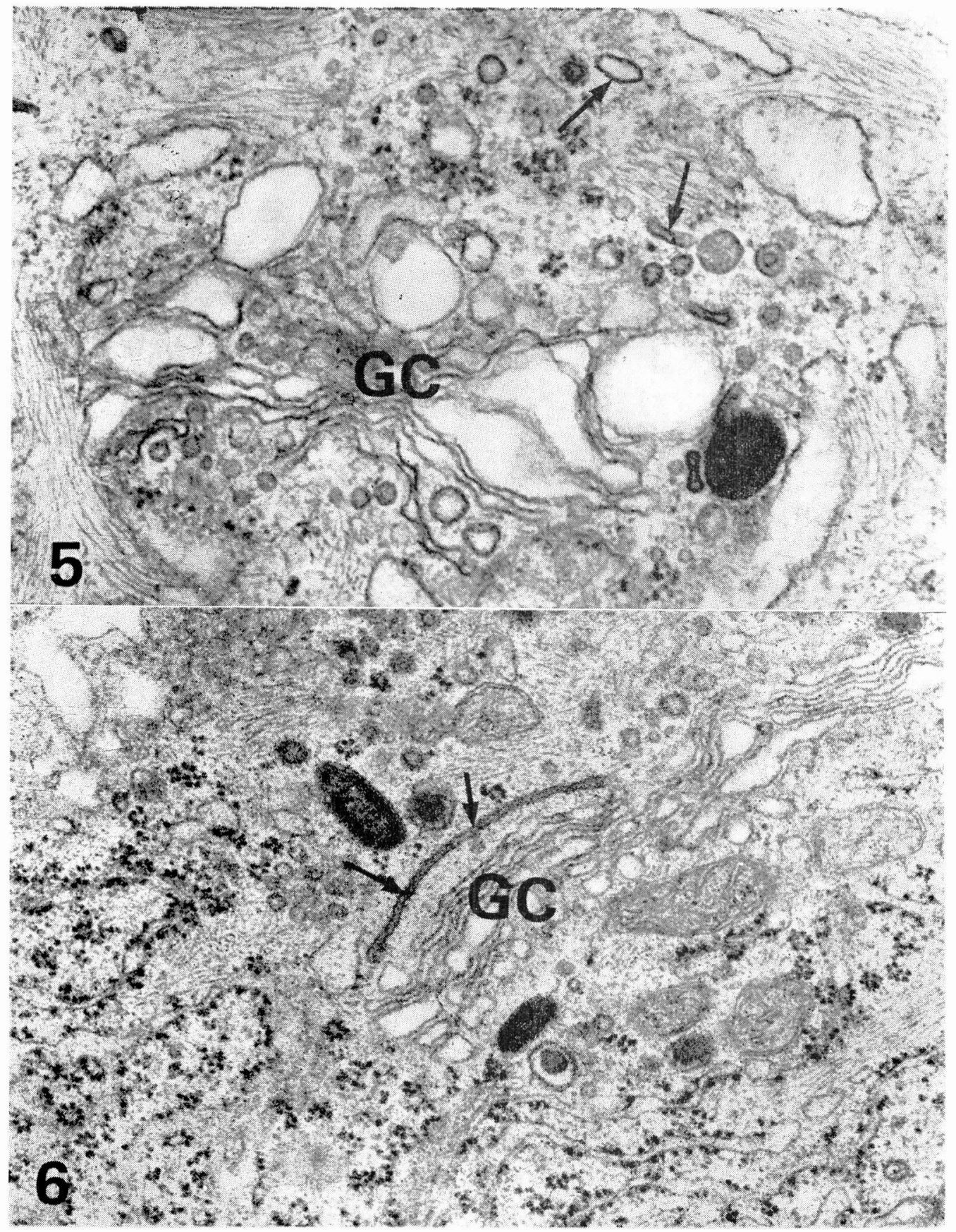

Fig. 5 Golgi complex (GC) of a type II cell. Many vesicles including thick-walled ones (arrows) exist in a vicinity of the Golgi region. $\times 50,000$.

Fig. 6 Golgi complex (GC) of a type II cells. Unit membrane of the cisternae in the distal face increases the density and the thickness (arrows). $\times 38,000$. 


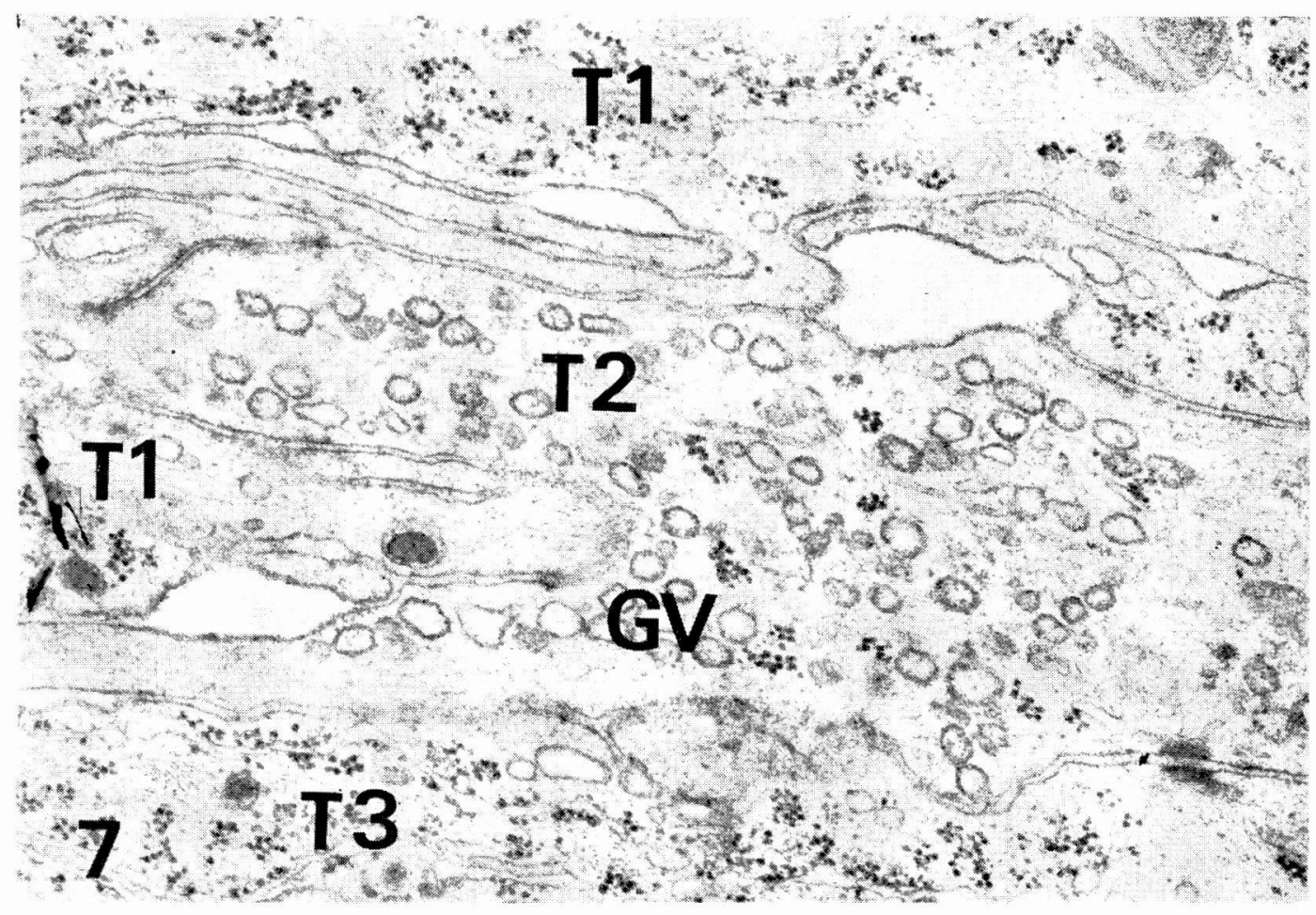

Fig. 7 An aggregation of Golgi-derived vesicle (GV) in the apical part of a differentiating type II cell (T2). T1 and T3; differentiating type I and III cells. $\times 39,000$.

rase activity on the limiting membranes and interior core (Fig. 10). A second type of vesicles has the size range of $40-60 \mathrm{~m} \mu$ in diameter and general appearance of vesicles frequently described in synaptic regions (so-called synaptic vesicles). However, both have no evidence that they are assembed in the Golgi complex and never flow to the apical cell cytoplasm. They are usually accumulated around nucleus and near the synaptic region ${ }^{10)}{ }^{16}$.

\section{Cytochemical characteristics of the Golgi-derived vesicles}

The apical plasma membrane comprisig the microvilli basically has unit membrane structure, but their outer leaflet becomes slightly thicker and denser than that of lateral cell mem- brane, mostly due to the existence of the surface coat (Fig. 11).

ATPase activity as dense deposits of lead phosphate is localized on the plasma membranes in the taste bud cells and in the space between them as so in other cells but exclusively intense reactions for the activity are observed in the region of the microvilli (Fig. 12).

Intense reactions for acid mucopolysaccharide by $R R$ are also localized in the taste pit region (Fig. 13). At higher magnification, the outer leaflet of the cell membrane comprising the microvilli increases their density by RR-positive material (Fig. 14). Dense substances between the microvilli are not an RR-positive region. These findings are similarly noted by colloidaliron staining. By this method, colloidal 


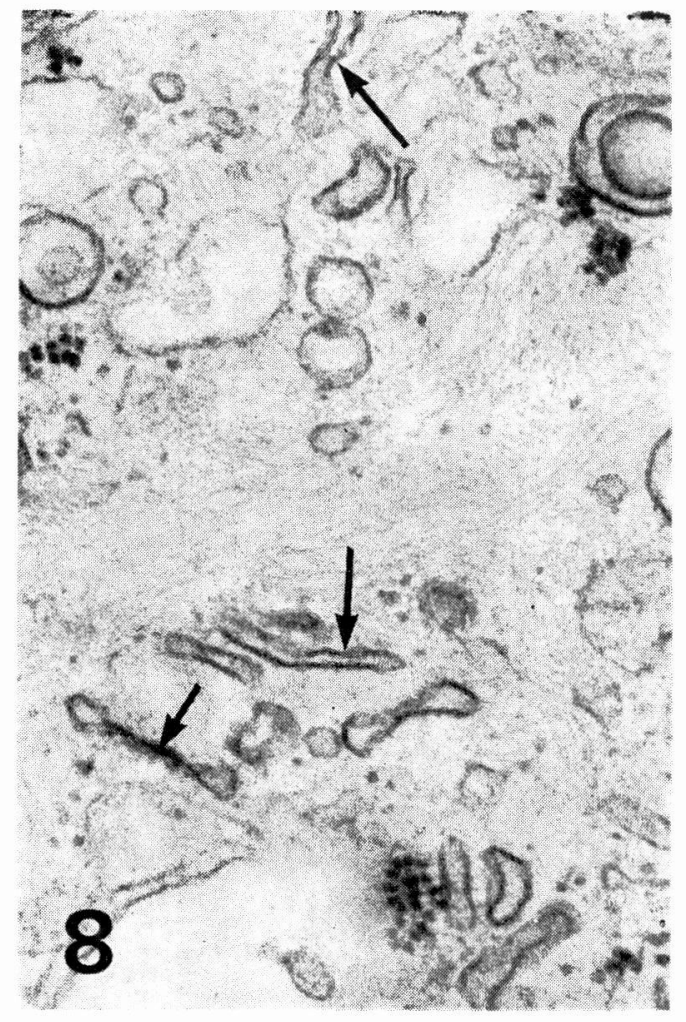

Fig. 8 Thick-walled, fusiformig Golgi-derived vesicles in a type II cells (arrows). $\times 62,000$.

iron particles is heavily attached to the outer leaflet of the unit membrane of the microvilli (Fig. 15).

$R R$-positive sites are also found within the taste bud cells. It is the limiting membrane of the Golgi-derived vesicles. In higher magnification of this illustration, intermediate electron lucent area in the limiting membrane of the dark granules in the type I cells between the outer and the inner leaflet encases the RR-positive material (Fig. 16). Sometimes, $R R$-positive material appears attached to the surface of the limiting membrane (Fig. 17). Similar findings are also noted in Golgi-derived vesicles of the type II and III cells (Fig. 18). Other limiting membranes of the intracytoplasmic organelles, such as endoplasmic reticulums, mitochondria and lysosomes are unstained by RR. Furthermore, two kinds of vesicles uniquely occured in the type III cells, which have no direct evidence for Golgiorigin, do not contain RR-positive material.

\section{DISCUSSION}

Beidler and Smallman ${ }^{3)}$ showed by autoradiography that taste cells degenerate and are replaced by newly differentiated ones from perigemmal epithelial cells in the normally innervated taste buds. The dependence of the cell renewal in taste buds on an intact nerve supply was also demonstrated by our electron microscopy ${ }^{8)}{ }^{91}$. Actually, we can find some cell profiles in a normal bud which appear degenerating or differentiating. Therefore, by an observation on considerable numbers of the sampling, we can encounter many differentiating cells of various degrees and, by them, we can assemble the differentiation process of the taste bud cells The cell differentiating are firstly noted by slight changes in the epithelial cells surrounding the taste bud. These include decrease of prominent tonofibrile bundles, increased smoothness of outer line and lighter appearing cytoplasm (basal cell). The second process is distinctly different between each cell type and the cells become designable as unmatured form of the other three cell types. In this step, formation of vesicles is begun in the Golgi complex and they become appearing in considerable number in the supranuclear cytoplasm, especially as an aggregation just beneath the apical plasm membrane before and during the formation of the microvilli. Their fusion with each other and with the plasma membrane are frequently notified.

These findings may support the hypothesis, pointed out by previous 


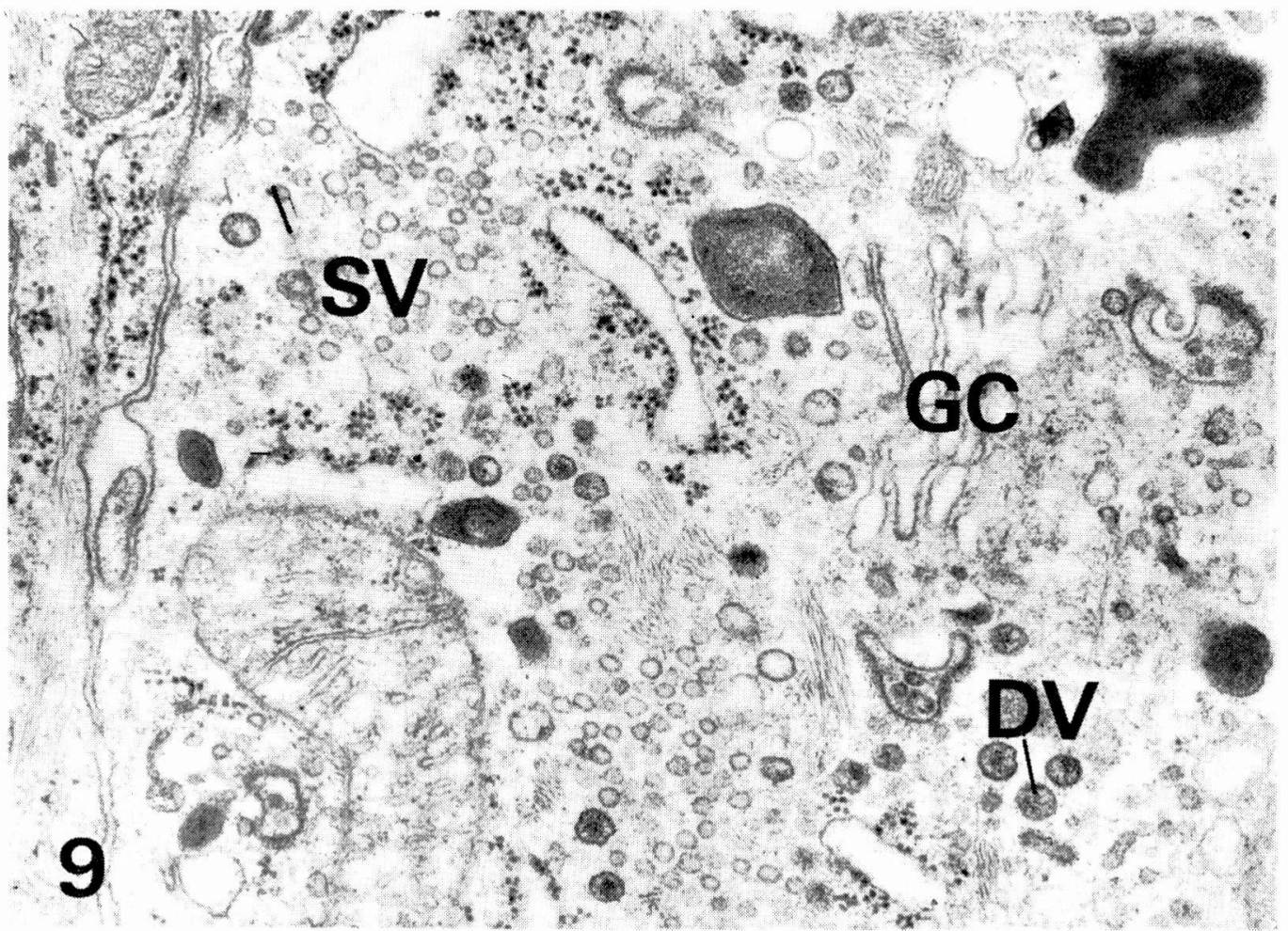

Fig. 9 Two kinds of vesicles uniquely occurred in type III cell : one (SV) is similar in feature to synaptic vesicles, and another (DV) is dark cored vesicles. GC; Golgi complex. $\times 34,000$.

workers ${ }^{7 / 20)}$, that Golgi-derived vesicles provide membranes for the morphogenesis of microvilli as "surface forming vesicles". This hypothesis means that microvilli specialization arises not only by self-assembly process of molecules at the surface membrane itself but also as a result of a mediation by Golgiderived vesicles.

In our specimens, this interpretation involves secretory functions of granules in the type I cells. Furthermore, integration of the Golgi-derived vesicles into the plasma membrane at free cell surface seems to continue after the microvilli specialization has been accomplished; similar events are also marked in the matured form although less-pronounced. This can hardly be ex- plained simply by this hypothesis because the matured form has already possessed enoughly-developed microvilli which length and number per cell seem to be limited in the taste bud cells.

However, many extracellular vesicular components are observed between the microvilli, and the membrane limiting these vesicle resembles morphologically the plasma membrane of microvilli (Fig. 11). Therefore, it is quite reasonable to assume that these vesicles have been pinched out from the plasma membrane of microvilli. Thus, constant renewal (or replacement) of partial units of the free surface membrane should be considered in a normal bud, and we could, furthermore, speculate that a quantative balance between supply and 


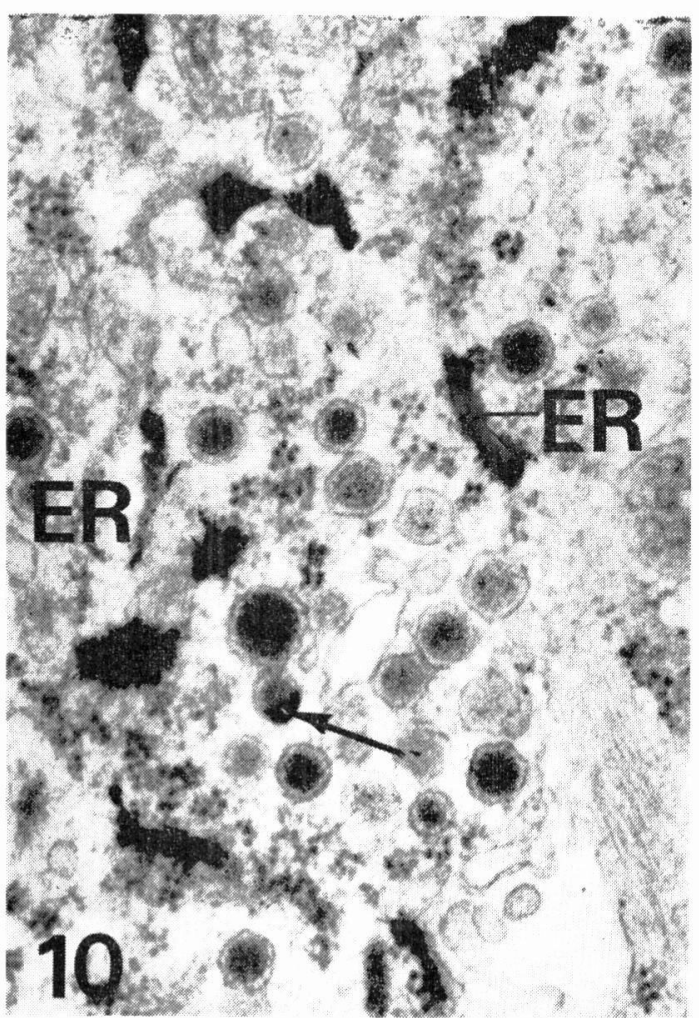

Fig. 10 Acetylcholinesterase activities of a type III cell. Intense reactions are found in cisternae of $\mathrm{rER}(\mathrm{ER})$, and the limiting membrane of dark cored vesicles (arrows). $\times 54,000$.

loss of the plasma membrane by vesicles of the microvilli might be essential to maintenance of the microvillous structure of a taste bud cell ; when the latter process predominates, the microvilli will become deforming as so in degenerating cells $^{8)}{ }^{9)}$. What a significance this replacement has is very difficult to say from our data and will be briefly referred in the end of this article.

It is widely-accepted physiologically as well as morphologically that the plasma membrane of the microvilli is sites where a taste bud cell combines initially with various taste substances. However, how the taste bud cell responses against them has scarcely been elucidated. By histochemistry and electrophysiology, this initial responsetriggering process has been tried to explain but is quite controversial. Baradi and Bourne ${ }^{1)}$ believed, by their lightmicroscopic histochemistry, that the resting state of the taste cell membrane is dependent upoin localizing nucleoside phosphatase of the membrane; when the enzymes are inactivated by a combination with taste substance, the resting state is disrupted and the cell is stimulated. Rakhawy ${ }^{18)}$ proposed a role for alkaline phosphatase in absorption of taste substances through the unit membrane.

On the other hand, Beidler ${ }^{2)}$, using his electrophysiological data, insisted that taste substances are not "absorbed" but "adsorbed" to the receptor membrane, and noted that the membrane enzymes are not involved in the initial response-triggering process but play a role in providing the metabolic energy for receptor potentials of the cells. Intense ATPase activities of the microvilli membrane by the present study could support his hypothesis since this enzyme produces high energy by a hydrolyzation of ATP. However, roles for this ATP-ATPase system in taste transduction is in need of further investigation at macromolecular level.

Intense reaction for acid mucopoly saccharide on the surface of the microvilli was demonstrated. Acid mucopolysaccharide possesses all of the defining characteristics of the glycocalyx, a term generalized by Bennett ${ }^{5}$ to all external surface coats of plant and animal cells, and is composed of sugars, proteins, and acidic groups such as hyaluronic acid or sialic acid. It has been suggested 


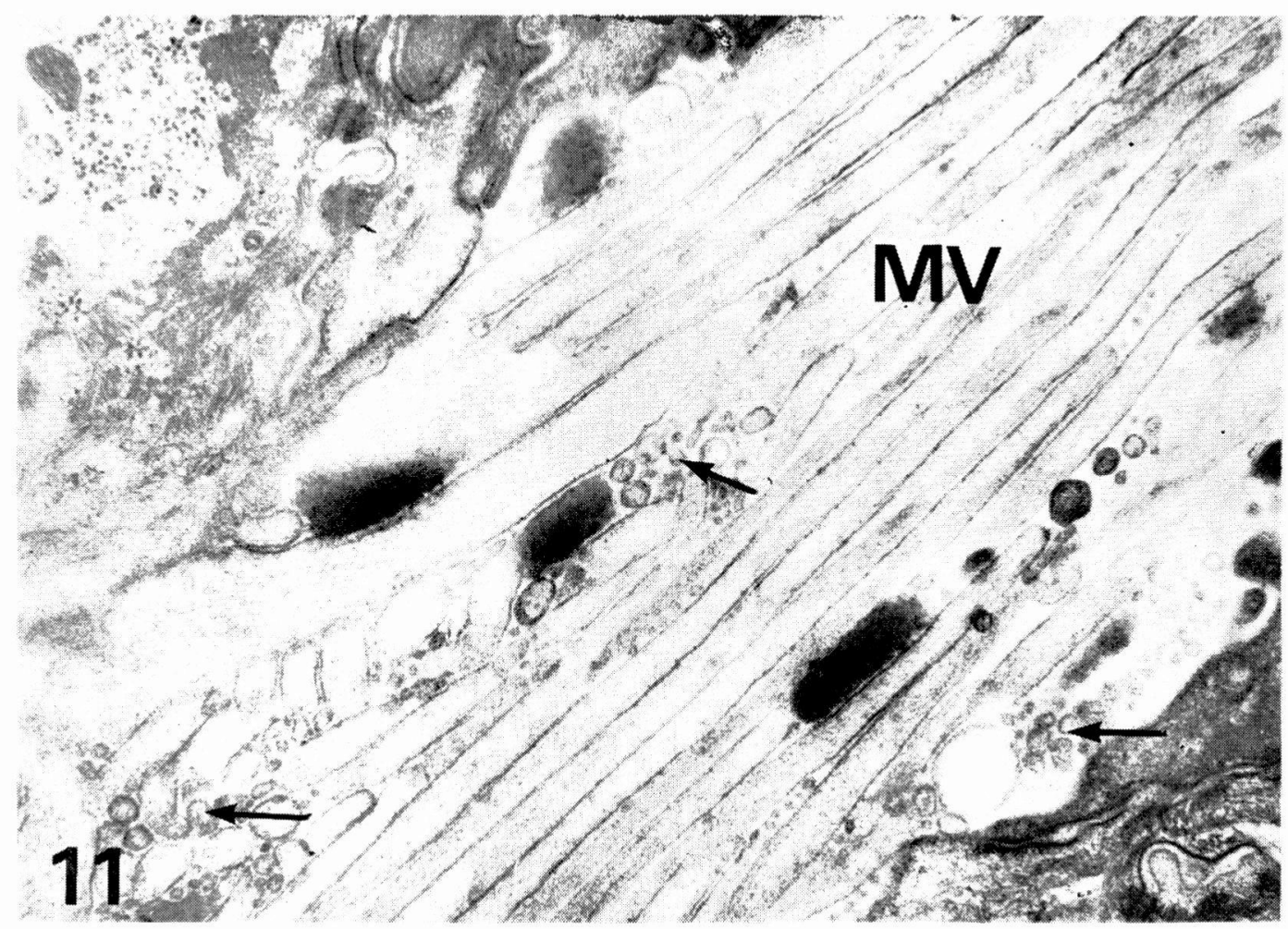

Fig. 11 Microvilli of the taste bud cells (MV). Many extracellular vesicles pinched out from the plasma membrane (arrows) exist between the microvilli. $\times 42,000$.

that acid mucopolysaccharide-rich surface coat represents a functional zonation of the membrane enzymes and play an important role in absorptive, and pinocytotic activitities of cell; roles in ion-trap, anchoring sites to calcium ions, and potassium transport have been suggested. On this basis, some selectivity of ions or molecules through meshes of acid mucopolysaccharide coat at cell surface must be considered in a passage of taste substances to the membrane of the taste bud cells. Since the surface of the microvilli are negatively charged by acidic radicles of acid mucopolysaccharide, cation groups of taste substances would be more selectively reacted to the membrane. This speculation favors for data by Beidler ${ }^{2}$ that reacting anionic molecular groups of the receptor membrane are strong acidic radicles and, therefore, the cations of taste substances are most effective in taste stimulating process, while the anions help to determine the magnitude of the response.

Acid mucopolysaccharide is assembled in the Golgi complex and incorporated into the plasma membrane as surface coa $t^{4(6) 19) 22)}$. However, we have no exact chemical maps of surface coat between different cells. Further cytochemical digestive test and biochemistry of the surface coat are necessary, and such 


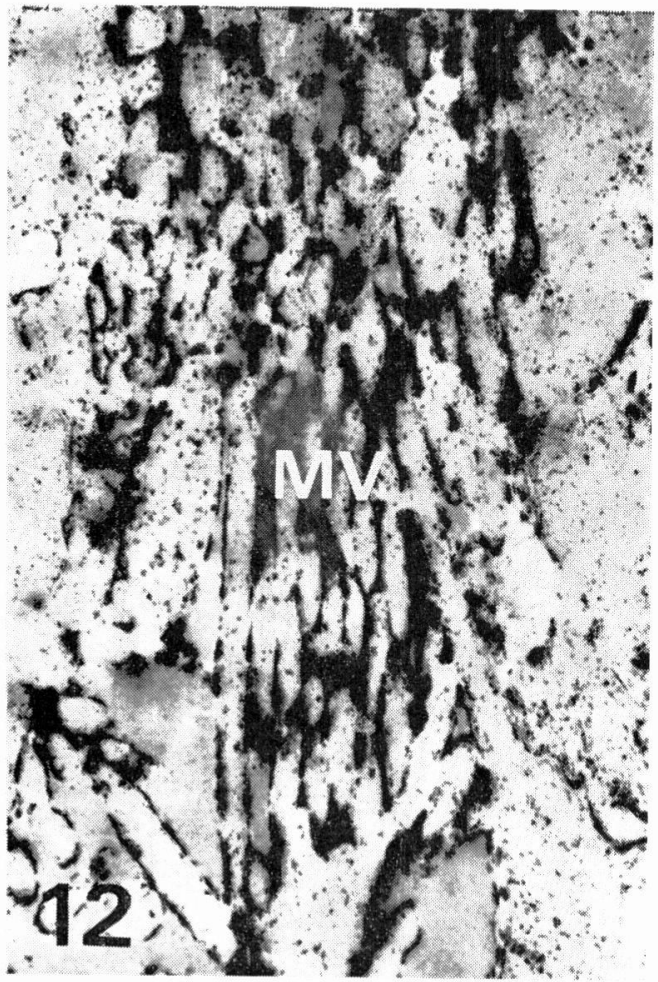

Fig. 12 Intense ATPase activity localized on the plasma membrane of the microvilli (MV). Unstained section. $\times 22,000$.

studies may give some hints to problems puzzling us how each taste cell has different sensitivities for different taste substances.

It has been considered that $R R$ can hardly penetrate the intact cell membrane and that intracytoplasmic penetration of $R R$ only occurs after mechanical damage of the cell surface.

Therefore, examples of positive reaction for intracytoplasmic organelles have been limited. However, our present staining procedure shows intense RRpositive reaction for Golgi-derived vesicles.

Except for Golgi-derived vesicles, no other intracytoplasmic membranes such as those of mitochondria, endoplasmic reticulums and microtubles were not stained. This means that Golgi-derived vesicles have high affinity for $R R$ and, therefore, have a higher concentration of acid mucopolysaccharide material.

Thus, our observations strongly indicate that Golgi-derived vesicles represent preformed units of the plasma membrane, providing the membrane it self and surface coat material in the formation of microvilli. Autoradiographic study indicated renewal of surface coat ${ }^{11)}$. Extracellular vesicles between the microvilli of the taste bud cells may be involved in this renewal process of surface coat material.

Fig. 13 Positive reaction sites for acid mucopolysaccharide by $\mathrm{RR}$ in taste pore region. Surfaces of the microvilli (MV) is intensely stained. The limiting membrane of dark granules of type I cells are also stained (arrows). Unstained section. $\times 18,000$.

Fig. 14 Cross section of a taste pit region. RR reacts with the outer leaflet of the plasma membrane of the microvilli (MV). Dense substance (DS) is not stained. Unstained section. $\times 52,000$. 

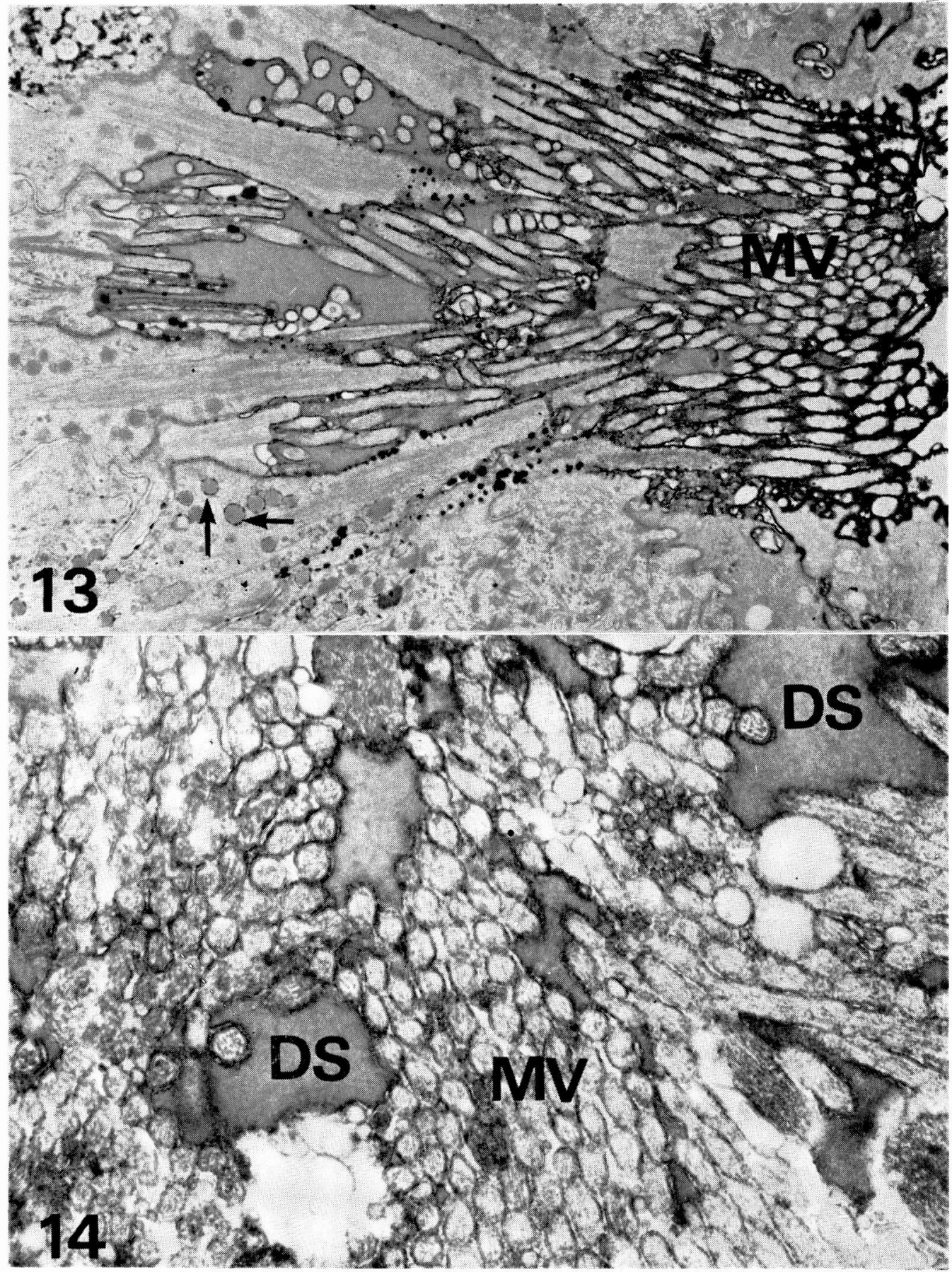


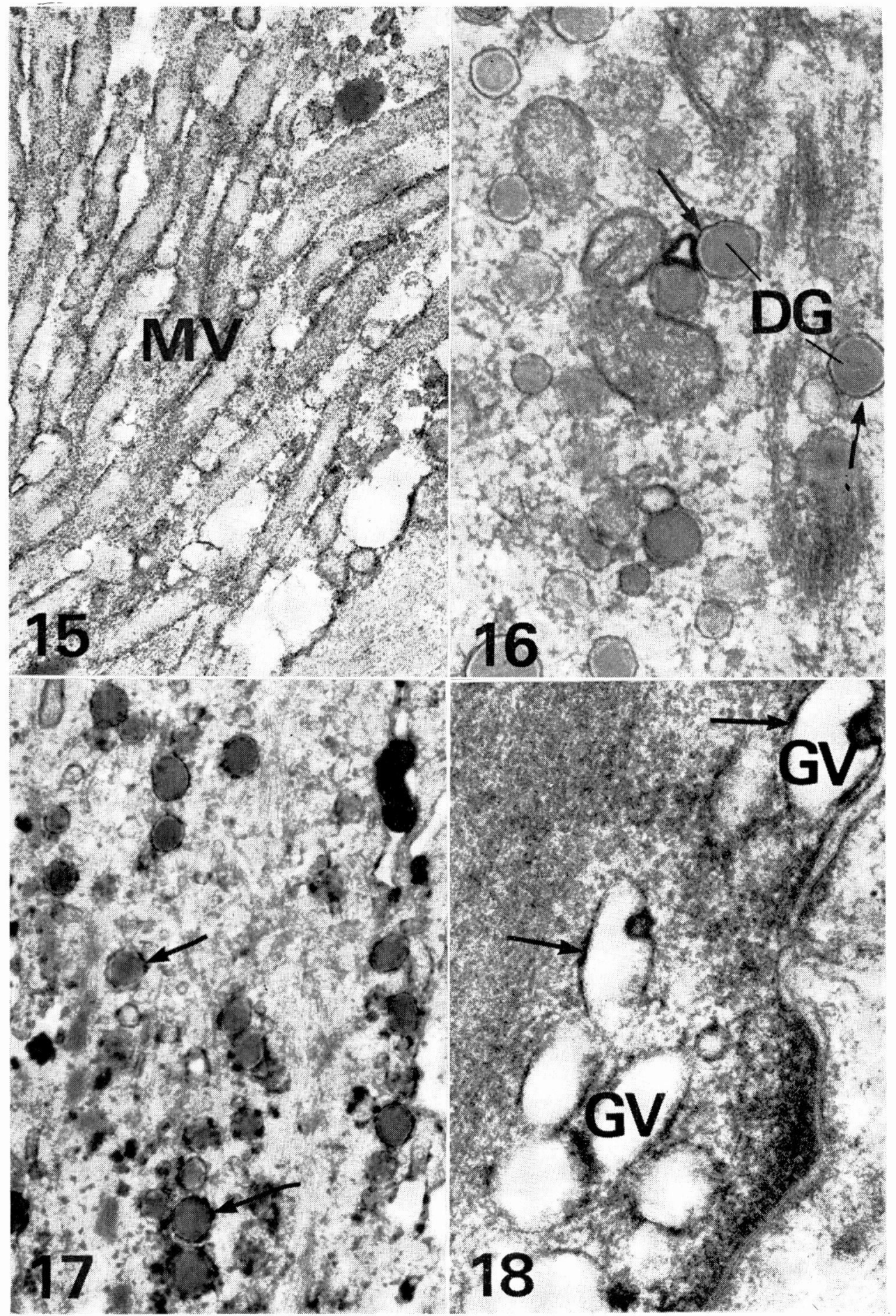


Fig. 15 Acid mucopolysaccharide staining by colloidal iron shows intense deposits on the surface membrane of the microvilli (MV). Unstained section. $\times 44,000$.

Fig. 16 Intermediate area of the limiting membranes of dark granules (DG) in a type I cell increases the density by RR-positive material (arrows).

Unstained section. $\times 55,000$.

Fig. 17 RR-positive materials attached to surface of the limiting membrane of dark granules in a type I cell (arrows). $\quad \times 38,000$.

Fig. 18 Intermediate area of the limiting membranes of Golgi-derived vesicles (GV) in a type II cell also encases RR-positive material (arrows). $\quad \times 91,000$.

\section{REFERENCES}

1) Baradi, A. F. and Bourne, G. H. : Localization of gustatory and olfactory enzymes in the rabbit. Nature (Lond.), 168, 977, 1951.

2) Beidler, L. M. : Theory of taste stimulation. J. gen. Physiol., 38, 133, 1954.

3) Beidler, L. M. and Smallman, R. L. : Renewal of cells within taste buds. J. Cell Biol., 27, 263, 1965.

4) Bennett, G. and Leblond, C. P. : Formation of cell coat material for the whole surface of columner cells in the rat small intestine, as visualized by radioautography with L-fucose- ${ }^{3}$ H. J. Cell Biol., 46, 409, 1970.

5 ) Bennett, H. S. : Morphological aspects of extracellular polysaccharides. J. Histochem and Cytochem., 11, 14, 1963.

6 ) BERLIN, J.D. : Early irradiation effects on the localization of acid mucopolysaccharide in intestinal absorptive cells. J. Cell Biol., 35, 12A, 1967.

7 ) Bonneville, M. A. and Weinstock, M. : Brush border development in the intestinal absorptive cells of xenopus during metamorphosis. J. Cell Biol., 44, 151, 1970.

8 ) Fujimoto, S., Murray, R. G. and Murray, A. : Some observations of changes in denervated taste buds of circumvallate papillae of rabbits. In: Electron Microscopy. Twenty-seventh Annual Proceedings of EMSA. C. J. Arceneaux, ed. Claitor's Publishing Div., Baton Rouge, pp. 308, 1969.

9) Fujimoto, S. and Murray, R. G.: Fine structure of degeneration and regeneration in denervated rabbit vallate taste buds. Anat. Rec., 168, 393, 1970.
10) Fujimoto, S. : Fine structure and functions of the taste bud cells. J. Jap. Med. Assoc. 69, 1421, 1973. (in Japanese)

11) Ito, S. and Revel, J. P. : Autoradiography of intestinal epithelial cells. In : Electron microscopy. Six International Congress for Electron Microscopy. R. Uyeda ed. Marzen Co., Ltd. Tokyo, 2, pp. 585, 1966.

12) Lewis, P. R. and Shute, C. C. D. : The distribution of cholinesterase in cholinergic neurons demonstrated with electron microscope. J. Cell Sci., 1, 381, 1966.

13) Luft, J. H. : Ruthenium red staining of the striated muscle cell membrane and the myoendinal junction. In: Electron microscopy. Six International Congress for Electron Microscopy. R. Uyeda ed. Maruzen Co., Ltd. Tokyo 2, pp. 65, 1966.

14) Luft, J. H. : Ruthenium red and violet. II) Fine structural localization in animal tissue. Anat. Rec. 171, 369, 1971.

15) Mowry, R. W. : Improved Procedure for the staining of acidic polysaccharide by Müller's colloidal (hydrous) ferric oxide and its combination with the Feulgen and the Periodic Acid-Schiff reactions. Laborat. Invest., 7, 566, 1958.

16) Murray, R.G., Murray, A. and Fujimoto, S. : Fine structure of gustatory cells in rabbits taste buds. J. Ultrastruct. Res., 27, 444, 1969.

17) Murray, R. G. and Fujimoto, S. : Demonstration of cholienesterase in rabbit foliate taste buds. In: Microscopic Électronique. Seventh International Congress for Electron Microscopy, 3, pp. 38, 1970. 
18) RAKHAWY, M. T. E. : Alkaline phosphatases in the epithelium of the human tongue and a possible mechanism of taste. Acta anat. (Basel), 55, 323, 1963.

19) Rambourg, A., Hernande $Z$, W. and Leblond, C. P. : Detection of complex carbohydrates in the Golgi apparatus of rat cells. J. Cell Biol., 40, 395, 1969.

20) RÖHLICH, P. : Formation of the brush border by fusion of vesicles. In: Electron microscopy. Fifth International Congress for Electron Microscopy, S. S. Breese, Jr., ed., Academic Press Inc., N. Y. 2, pp. LL5,1972

21) Wachstein, M. and Meisel, E. : Histochemistry of hepatic phosphatases at a physiologic pH. Amer. J. Clin. Path. 27, 13, 1957.

22) Wetzel, M. G., Wetzel, B. K. and Spicer, S. S. : Ultrastructural localization of acid mucosubstances in the mouse colon with iron-containing stains. J. Cell Biol. 30, 299, 1966. 